Review

\title{
Offshore Geotechnical Problems in Deepwater Mooring Techniques for Large Floating Structures
}

\author{
${ }^{1,2}$ Haixiao Liu, ${ }^{1}$ Zhou Li and ${ }^{1}$ Yuming Zhang \\ ${ }^{I}$ State Key Laboratory of Hydraulic Engineering Simulation and Safety, Tianjin University, Tianjin 300072, China \\ ${ }^{2}$ Collaborative Innovation Center for Advanced Ship and Deep-Sea Exploration, \\ Shanghai Jiao Tong University, Shanghai 200240, China
}

Article history

Received: 29-03-2018

Revised: 13-04-2018

Accepted: 27-04-2018

Corresponding Author:

Haixiao Liu

State Key Laboratory of

Hydraulic Engineering

Simulation and Safety, Tianjin

University, Tianjin 300072,

China and

Collaborative Innovation

Center for Advanced Ship and

Deep-Sea Exploration,

Shanghai Jiao Tong University,

Shanghai 200240, China

Email: liuhx@tju.edu.cn

\begin{abstract}
An effective, reliable and economic positioning technique is of great necessity for offshore large floating structures. Within all techniques of station keeping, mooring plays a vital role for large floating structures. Clear knowledge of the role and particularities of mooring systems is important to the design, operation and analysis of large floating structures especially in deep waters. The present work aims to discuss the mooring techniques applied to deep waters. Surveys and statistical analysis are performed to highlight the strategic importance of deepwater mooring techniques. An engineering case is introduced to demonstrate the specialities of the deepwater mooring research. Different types of anchors which are applicable to deep waters are reviewed with emphasis due to the key role of anchors in the mooring system. Offshore geotechnical problems in deepwater mooring techniques as well as research advances are summarized for the ongoing and future studies.
\end{abstract}

Keywords: Offshore Geotechnical Engineering, Floating Structure, Deepwater, Positioning, Mooring System, Anchor

\section{Introduction}

Effective utilization of ocean space and rational exploitation of marine resources have already become a strategic goal of many countries in the world. Considering the particularities and extreme complexities of the marine environment, developing and utilizing innovative engineering technologies and facilities is vital to support various kinds of human activities in far and deep seas. For different types of offshore large floating structures, such as oil and gas platforms, seadromes, artificial islands and storage and transit bases, an effective, reliable and economic positioning technique is of great necessity. Positioning of floating structures can usually adopt three ways, including mooring, dynamic positioning and the hybrid of mooring and dynamic positioning. The techniques of mooring can be further divided into three categories, including the catenary, tension leg and taut-wire systems. Within the techniques of station keeping, mooring plays an important role for large floating structures.

For a large floating structure, the mooring system is a huge, complicated and integrated system in space, which confronts the whole ocean environments and links nearly all elements of the floating system from top to bottom, including the floater, mooring lines, anchors and so on. It may involve very long mooring lines with the single length of several kilometers and cover the anchorage area as large as hundreds or even over one thousand square kilometers, as demonstrated in Fig. 1. It is evident that the mooring system plays a special role for large floating structures. Clear knowledge of the role and particularities of mooring systems is important to the design, operation and analysis of large floating structures especially in deep waters. The present work aims to discuss the mooring techniques applied to deep waters. Surveys and statistical analysis are performed to highlight the strategic importance of deepwater mooring techniques. An engineering case is introduced to demonstrate the specialities of the deepwater mooring research. Different types of anchors which are applicable to deep waters are reviewed with emphasis due to the key role of anchors in the deepwater mooring system. Several offshore geotechnical problems in deepwater mooring techniques as well as research advances are summarized for the ongoing and future studies. 


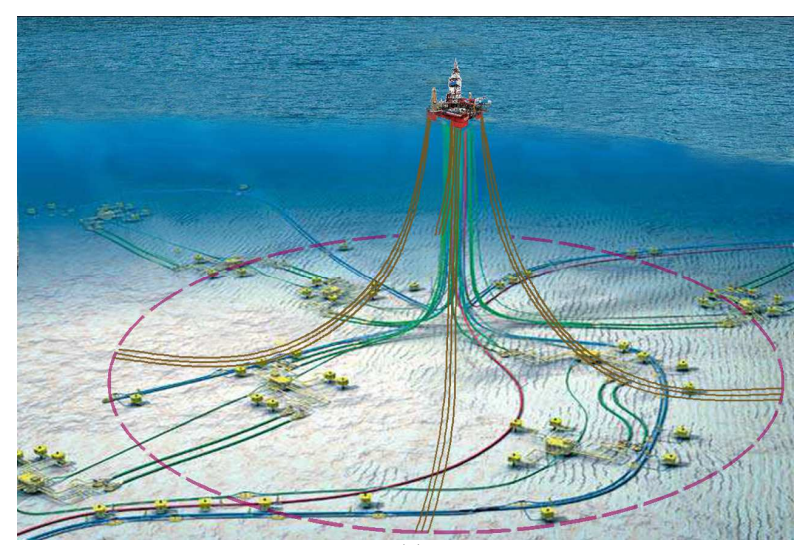

(a)

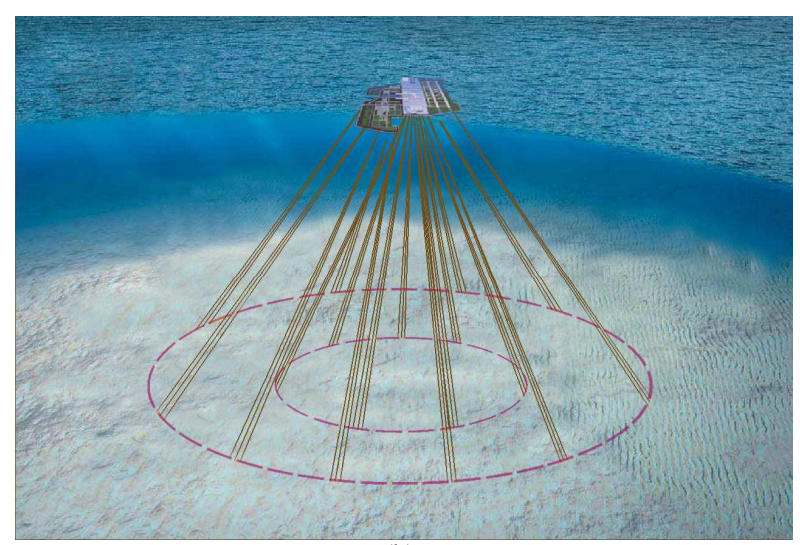

(b)

Fig. 1: Demonstration of the mooring system for large floating structures (a) Offshore oil and gas platform (b) Artificial floating island

\section{Strategic Importance of Deepwater Mooring Techniques}

\section{Positioning Techniques for Floating Oil and Gas Production Platforms}

A survey on 232 cases of floating oil and gas production platforms in water depths from 15 to $2600 \mathrm{~m}$, including FPSO, Spar, Semi, TLP and other types that came into operation from 1981 to 2015 , indicates that the most widely used technique is the Catenary Mooring System (CMS), taking up 55\%, followed by the Taut-wire Mooring System (TMS, 33\%), the Tension Leg Platform (TLP, 10\%) and the Dynamic Positioning (DP, 1\%) and the hybrid of mooring and Dynamic Positioning (CMS + DP, 1\%). If the water depth exceeds $500 \mathrm{~m}$, the most widely used technique becomes the taut-wire mooring system, taking up 59\%, followed by the catenary mooring system $(25 \%)$, the tension leg platform (15\%) and the dynamic positioning $(1 \%)$. If the water depth exceeds $1500 \mathrm{~m}$, the percentage of the taut-wire system rises to 83 , followed by the catenary system (14) and the dynamic positioning (3), as illustrated in Fig. 2 and presented in Table 1.

Since the first taut-wire mooring system adopting polyester ropes was installed by Petrobras in 1997, the TMS using synthetic fiber ropes has become a very attractive alternative to conventional steel catenary systems for the station keeping of all types of floating structures in deep waters (Nielsen and Bindingbø, 2000). Because the catenary system combining chain and wire ropes has a high in-water weight and a large footprint, it appears inefficient and costly in deep waters. Consequently, design consideration has been transferred to the TMS, which has been proved to be a better alternative for station keeping in deepwater locations. The TMS utilizes synthetic fiber ropes as mooring lines and deepwater anchors with higher pullout capacity and easier "installation" and presents a taut leg configuration in space. Compared to the conventional catenary system, there are many advantages of the TMS, such as efficient mooring performance, smaller footprint, easier installation, enhanced loading capacity and cost saving.

Based on the investigation above, conclusions as follows can be drawn: (1) Whether in shallow or deep waters, the mooring system is the commonly adopted positioning technique for floating oil and gas production platforms, occupying over $95 \%$, while the dynamic positioning and the hybrid are relatively rare; (2) The TMS is applicable to both shallow and deep waters, but becomes more common with increasing water depth, especially to ultra-deep waters; (3) The TMS is the most widely adopted technique for long-term and permanent positioning in deep waters. It is not only an advanced technique for deepwater positioning, but also a future choice of large mooring systems in deep and ultra-deep waters; (4) For the floating structures with certain mobility like oil and gas production platforms, the mooring system is still the basic and common positioning technique. For long-term and almost permanent positioning such as for artificial islands and seadromes, the mooring system is necessarily the preferential choice.

\section{Factors that Induce Severe Accidents of Offshore Oil and Gas Platforms}

What calls for special attention is, besides the function of positioning, the mooring system also plays a vital role in security assurance of large floating structures in the harsh marine environments. As indicated by engineering practice, the occurrence of catastrophic failure in deepsea engineering, such as capsizal, fracture, leaking, drifting out of control and collision, is more frequent in the extreme marine environments. The mooring system is a huge, 
complicated and integrated system in space, which links nearly all elements of the floating system from top to bottom. Once the mooring system fails, the whole floating system would suffer a catastrophe, or even become a great threat of security against marine structures and facilities nearby. A detailed investigation on the cases of severe accident, failure and capsizal of floating platforms since 1964 demonstrates that, among all the 69 cases with clear factors, the number caused by failure of the mooring system is 47 , reaching the highest percentage of 68 , while the rest 32 is contributed by all other factors, as listed in Table 2 and demonstrated in Fig. 3.

Table 1: Basic types for positioning floating oil and gas production platforms

\begin{tabular}{lrcc}
\hline & & Number of cases & \\
Positioning & - & & \\
technique & 232 (water depth between $15 \sim 2600 \mathrm{~m})$ & 128 (water depth beyond $500 \mathrm{~m}$ ) & 30 (water depth beyond $1500 \mathrm{~m}$ ) \\
\hline TMS & 76 & 75 & 25 \\
CMS & 129 & 32 & 4 \\
TLP & 23 & 19 & 0 \\
DP & 2 & 2 & 0 \\
CMS + DP & 2 & 0 & 1 \\
\hline
\end{tabular}

Table 2: Cases of severe accident, failure and capsizal of floating platforms (69 cases)

\begin{tabular}{llllll}
\hline Factor & $\begin{array}{l}\text { Failure of } \\
\text { mooring system }\end{array}$ & $\begin{array}{l}\text { Blowout, leaking, } \\
\text { fire, blast }\end{array}$ & $\begin{array}{l}\text { Damage of the } \\
\text { floating structure }\end{array}$ & $\begin{array}{l}\text { Holistic incline } \\
\text { or capsizal }\end{array}$ & $\begin{array}{l}\text { Accidents in haul } \\
\text { and installation }\end{array}$ \\
\hline Number of cases & 47 & 10 & 6 & 4 & 2 \\
\hline
\end{tabular}

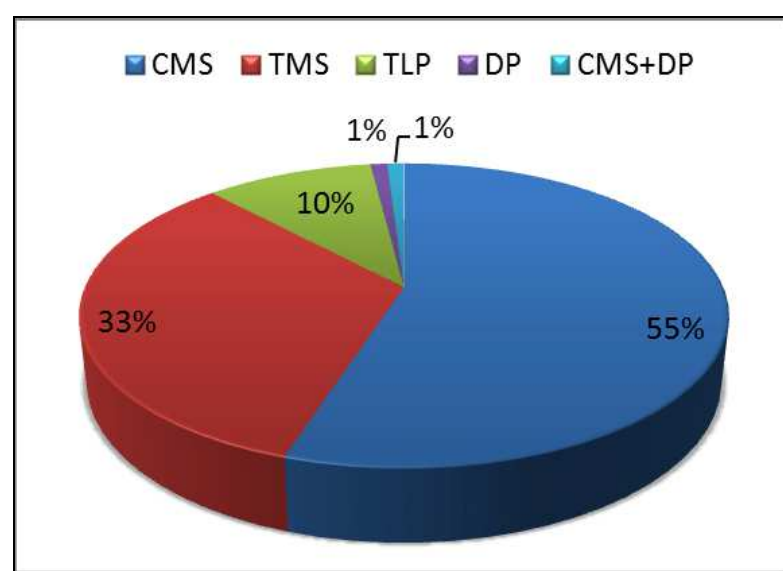

(a)

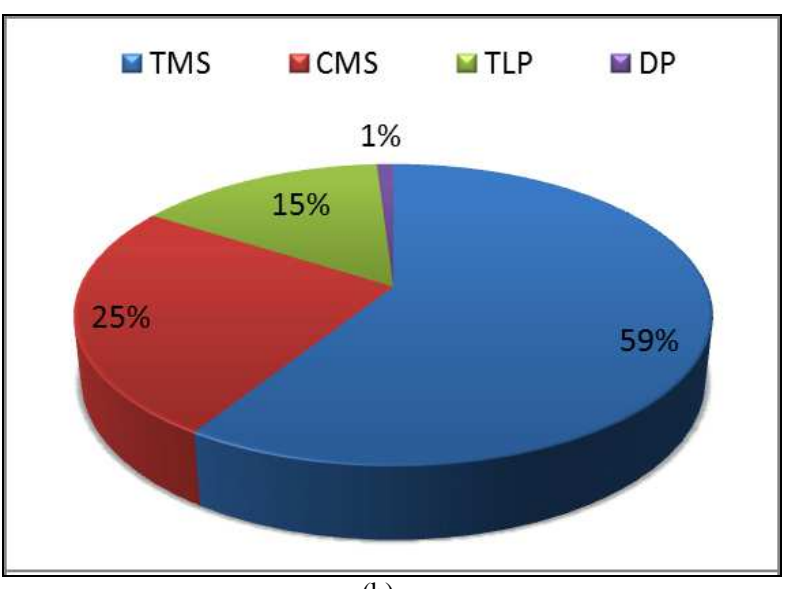

(b)

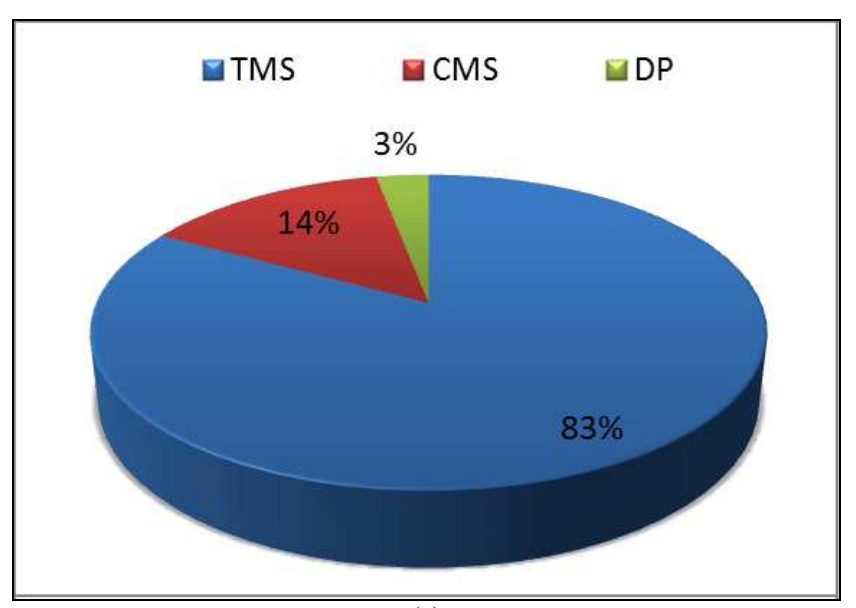

(c)

Fig. 2: Basic types for positioning floating oil and gas production platforms (a) Water depth between 15-2600 m (b) Water depth beyond $500 \mathrm{~m} \mathrm{(c)} \mathrm{Water} \mathrm{depth} \mathrm{beyond} 1500 \mathrm{~m}$ 


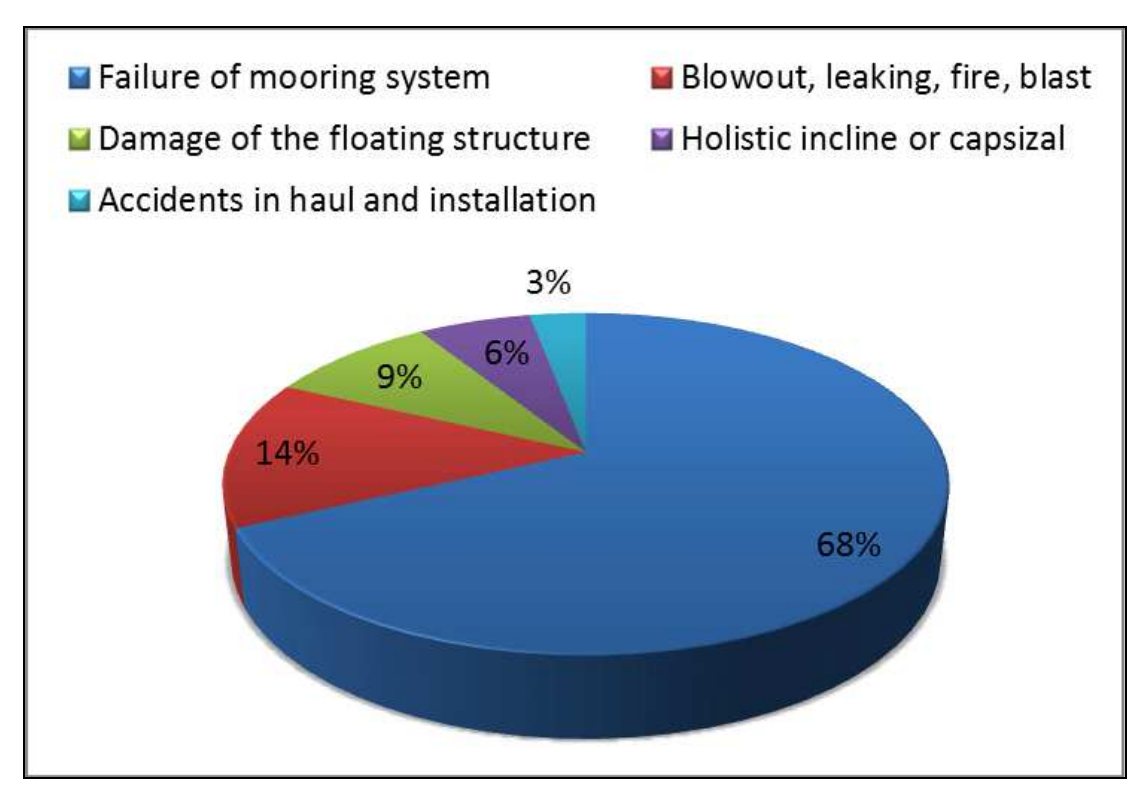

Fig. 3: Main factors that induce severe accidents of floating platforms

From the accident records, lessons as follows can also be learned: (1) Failure of the mooring system tends to occur in extreme environmental conditions such as violent storms; (2) Most severe accident, failure and capsizal of floating structures can be attributed to failure of the mooring system; (3) Failure of the mooring system would induce capsizal or long-distance drift (over $200 \mathrm{~km}$ ) of the floating structure and even severe secondary disaster; (4) With respect to failure of the mooring system, both anchors and mooring lines are likely to be out of function. For the mooring line, it may probably be broken, while for the anchor it may probably be pulled out from the seabed or further dive in the seabed with the drifting floating structure, depending on the type of anchors, soil property and loading conditions. Note that further diving of the anchor can effectively restrict drifting of the floating structure and therefore avoid possible severe secondary damage.

The significance of the mooring system to floating platforms, especially in providing safety insurance in extreme environmental conditions, can be obtained from the knowledge above. It is evident that, to exploit marine resources in far and deep seas with complicated and harsh environmental conditions, the design, installation and operation of the mooring system would be a great challenge.

The above surveys and statistical analysis demonstrate well the strategic importance of deepwater mooring techniques. Being a common and key technique for large floating structures, the deepwater mooring is the most efficient long-term and permanent positioning technique. Meanwhile, it plays a vital role in safety insurance of the floating structure during extreme sea environments. Due to that the mooring system is very sensitive to the water depth and is extremely risky and challenging part of the floating system, it is actually the bottleneck of ocean space utilization and resource exploitation in deep waters.

\section{Specialities of the Deepwater Mooring Research}

For deepwater mooring techniques especially the taut-wire mooring system, specialities may be brought about in design and analysis due to the special mooring pattern, material property of synthetic fiber ropes and performance of deepwater anchors.

An engineering case may demonstrate the specialities of the deepwater mooring research, as illustrated in Fig. 4 (Zimmerman et al, 2009). An eight-leg mooring system, in which eight OMNI-Max anchors were utilized, was installed for a MODU operating in the Mississippi Canyon area and experienced the Hurricane Gustav in 2008. When installed, all eight of the OMNIMax anchors achieved between 15.2 and $18.3 \mathrm{~m}$ of tip penetration. The MODU was on the northeast side of Hurricane Gustav's track and experienced maximum estimated $1 \mathrm{~min}$ wind speeds of greater than 100 knots. After Gustav passed, the MODU was found $3700 \mathrm{~m}$ northwest of its original location attached to only one of the eight OMNI-Max anchors. It was also observed that the original anchor penetrations all increased to a deeper depth, between 19.2 and $36.6 \mathrm{~m}$ of tip penetration. Figure 4a illustrates the intact pre-storm mooring pattern and the grounded segments of the mooring system surveyed with a ROV after Gustav (Zimmerman et al, 2009). 


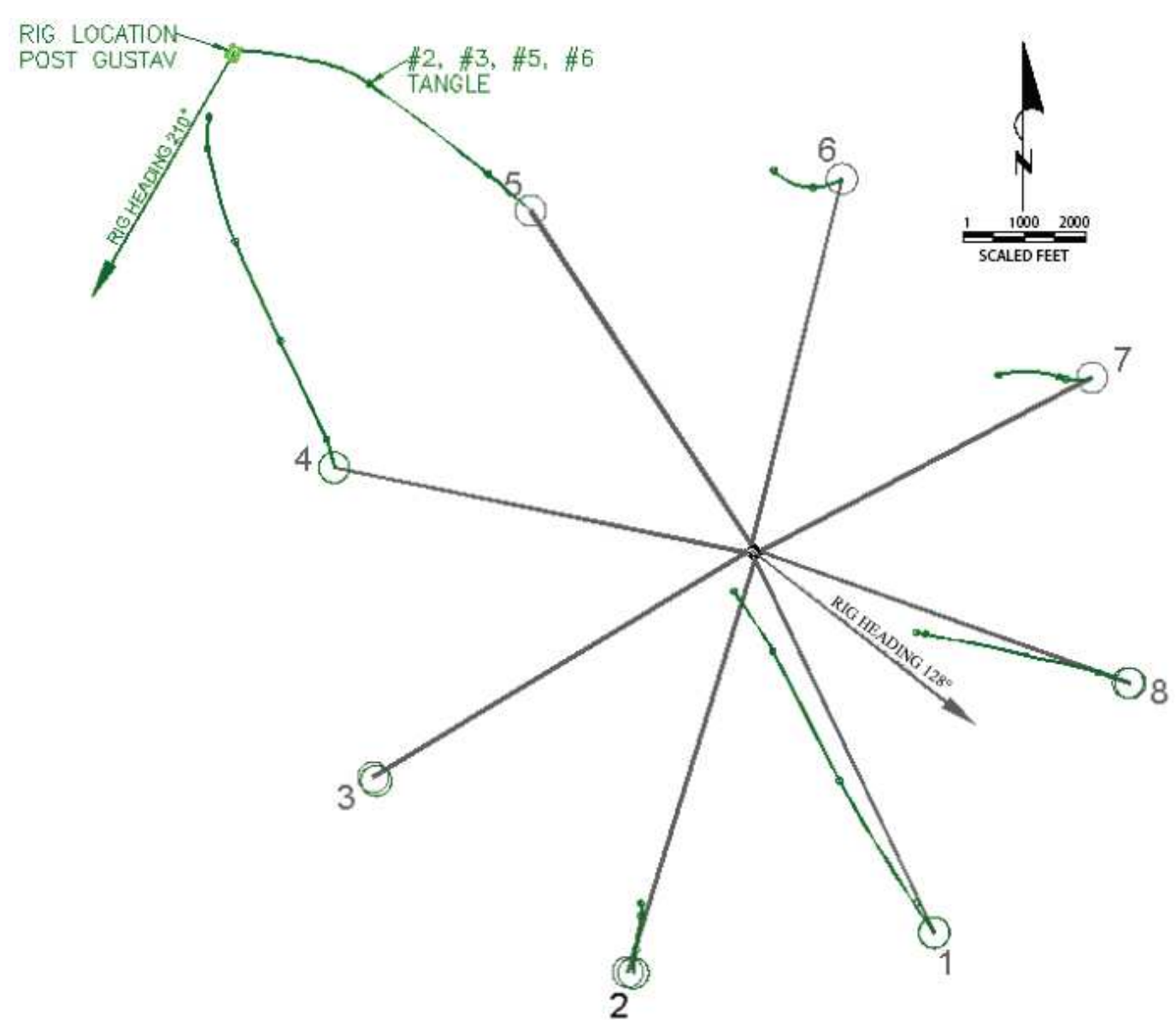

(a)

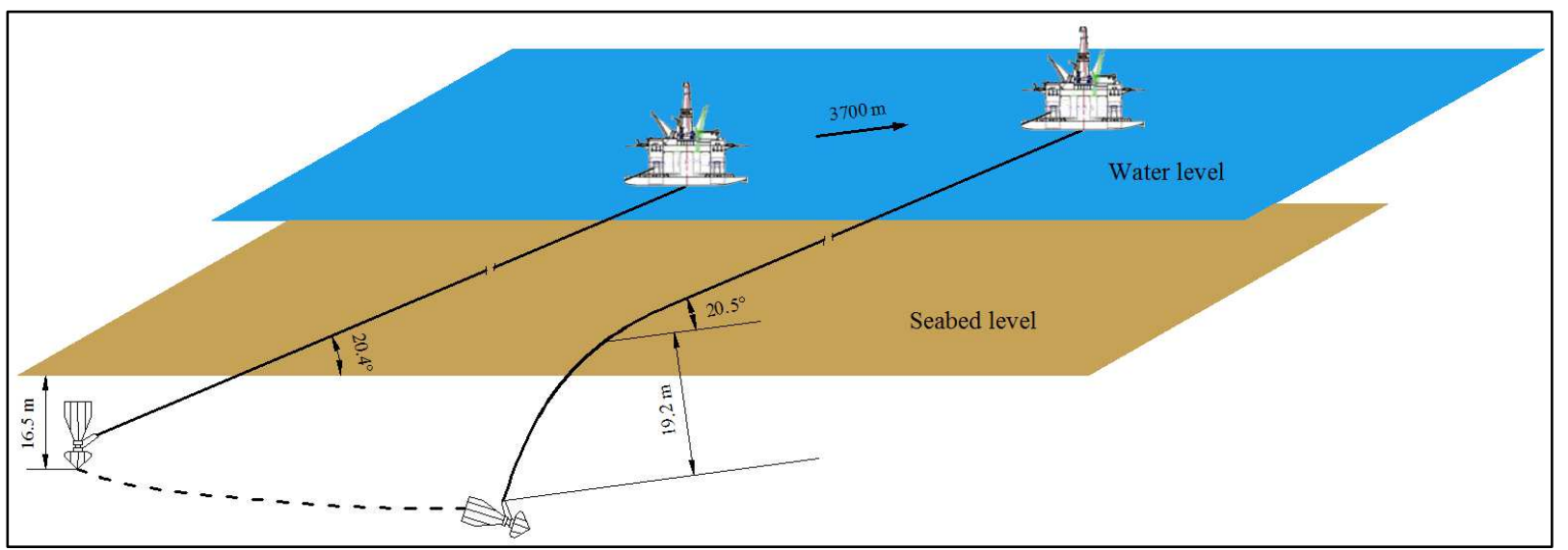

(b)

Fig. 4: Demonstration of the engineering case (a) Installed versus post Hurricane Gustav mooring pattern (Zimmerman et al., 2009) (b) Movements of the MODU, mooring line and anchor

This case tells us: (1) Unlike the conventional knowledge of the anchor failure, a large displacement or even long-distance movement of the anchor does not mean the failure of anchors, because the anchor still functions and exhibits a so-called non-catastrophic behavior; (2) The anchor exhibits more comprehensive behaviors in the seabed, such as keying, translating, diving and long-distance trajectory; (3) The mooring line embedded in soils is important to the anchor behavior, which transmits the tension and presents complex three- 
dimensional configuration due to soil resistance; (4) The movements of the floating structure, mooring line and anchor are noncoplanar, which increase the complexity of the deepwater mooring research; (5) Owing to the mechanical property of synthetic fiber ropes, which generally presents nonlinear and time-dependent behaviors due to the viscoelasticity and viscoplasticity of materials, the fatigue performance and durability of mooring ropes and the performance and dynamic response of the TMS become more complicated.

\section{Deepwater Anchors}

It should be noted that, within a large mooring system consisting of the floater, mooring lines and anchors, anchors are the core and root of the system. Since anchors are usually deeply embedded in the seabed and cannot be visually observed, the role of anchors are often undervalued or even ignored. However, the role of anchors to mooring systems is similar to that of the string to a kite. Without anchors as the effective and reliable root, the mooring system is no longer existent. With human activities increasingly moving to deep waters, anchors are very sensitive to the water depth within the whole floating "system" and are extremely risky and challenging during deepwater installation and operation. Therefore, deepwater anchors are the key technology of deepwater mooring systems. The TMS, which is an advanced technology for deepwater mooring as introduced earlier, requires higher pullout capacity of the anchor. Since the density of synthetic fiber ropes is close to that of seawater, the synthetic fiber ropes can stay taut while being pulled in seawater. This means that the response of the floater to wind, wave and current can be directly transmitted to anchors. On the other hand, the TMS also requires better performance of the anchor in deepwater installation, since this system is more often used in deep and ultra-deep waters. In the research and development of deepwater anchors, anchors with both excellent deepwater installation performance and pullout capacity have always been the goal of offshore engineering.

In deep waters especially with the depth exceeding $500 \mathrm{~m}$, anchors operate in a complicated environment with very harsh conditions, like invisibility, longdistance remote control, requirement of sufficient reliability and complex seabed environments. All these bring new challenges in installation, applicability, reliability and economy of the anchorage system. Driven by huge requirements of oil and gas exploitation, different concepts and technologies are continually emerging in pursuit of deepwater anchors with easier installation, better performance and lower cost. Meanwhile, researchers are devoted to dealing with new challenges raised by novel technologies in deepwater installation and operation. For instance, the simulation of the installation process of different anchors, the analysis and prediction of complex anchor behaviors in the seabed, the ability of the anchor to resist extreme environmental conditions and the analytical methods to guide the research and development of deepwater anchors.

Deepwater anchors are generally classified by the installation technique. Evaluated in deepwater installation, pullout capacity and economy and compared with the anchor pile, suction anchor and Suction Embedded Plate Anchor (SEPLA), there are two types of anchors, i.e., the drag embedment plate anchor (drag anchor) and the Gravity Installed Anchor (GIA), which are potential to be most widely adopted deepwater anchors. In addition to the differences in shape and structure, installation techniques of the two types are basically different. The drag anchor is pulled into the seabed through the installation line (Fig. 5), while the GIA penetrates into the seabed by free fall in seawater (Fig. 6). However, there are common features for the two types of anchors. Complex kinematic behaviors in the seabed, such as keying, translating, diving and specific trajectory, would arise under the action of installation or mooring lines (Fig. 7). Due to the specific installation technique, structural performance and complexities of marine environments, there are lots of interesting technical and scientific problems for deepwater anchors no matter in installation or mooring, which are deserved to be further investigated. For instance, the penetration mechanism and kinematic model of the anchor, the failure mechanism and failure mode of the anchor, high strain rate response of soils induced by high-speed penetration of the anchor into seabed and complex kinematic behaviors of the anchor in the seabed including conditions and properties of keying, diving and translating. All these problems need to be solved by developing new analytical methods through combining the mechanism, theory, experiment and numerical simulation. The associated techniques and methods have been the research highlights in deepwater mooring technologies and in the field of offshore geotechnical engineering.

A statistical analysis is also performed on anchors based on the 232 cases of floating oil and gas production platforms, as introduced earlier. However, only 173 cases can be used with definite anchor information, as summarized in Table 3 and illustrated in Fig. 8 and 9. It is well demonstrated that, the suction anchor, driven pile and drag anchor are most common choices for floating oil and gas production platforms and have been successfully applied to deep waters especially for suction anchors and driven piles. This analysis may also indicate that there are more challenges and values in the research and development of drag anchors, GIAs and SEPLAs, compared to suction anchors and driven piles. 


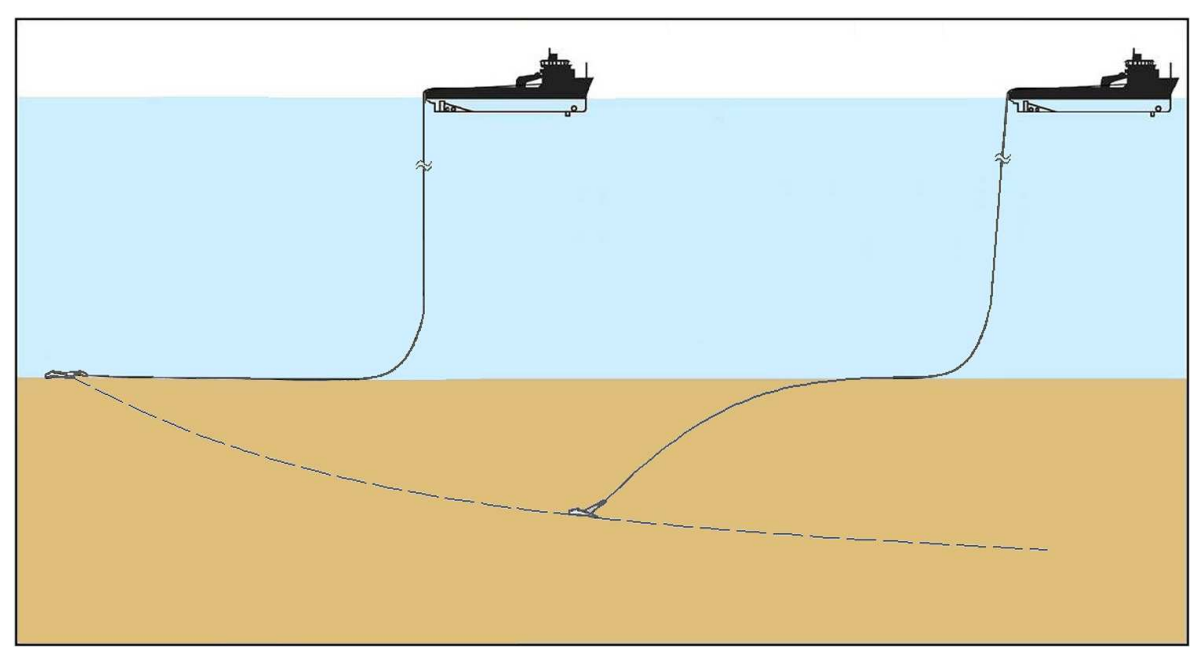

Fig. 5: Installation of the drag anchor and the trajectory in seabed

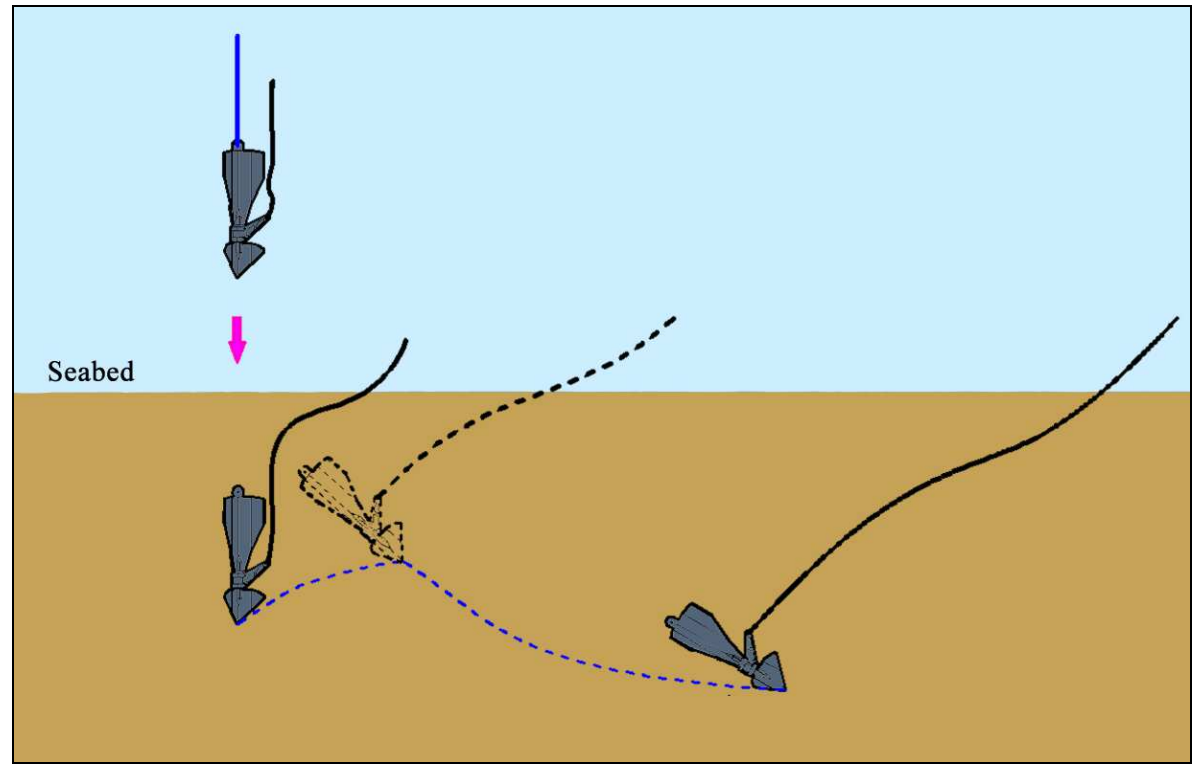

Fig. 6: Installation and behaviors of the gravity installed anchor in seabed

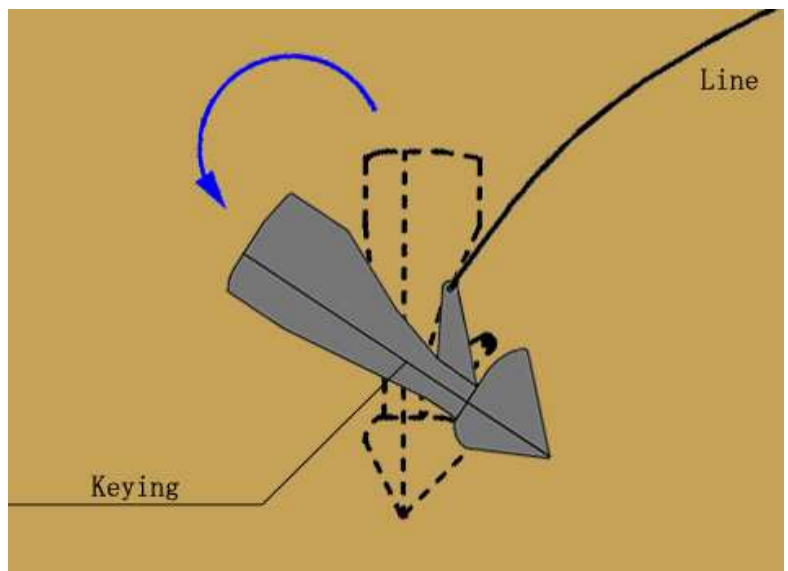

(a)

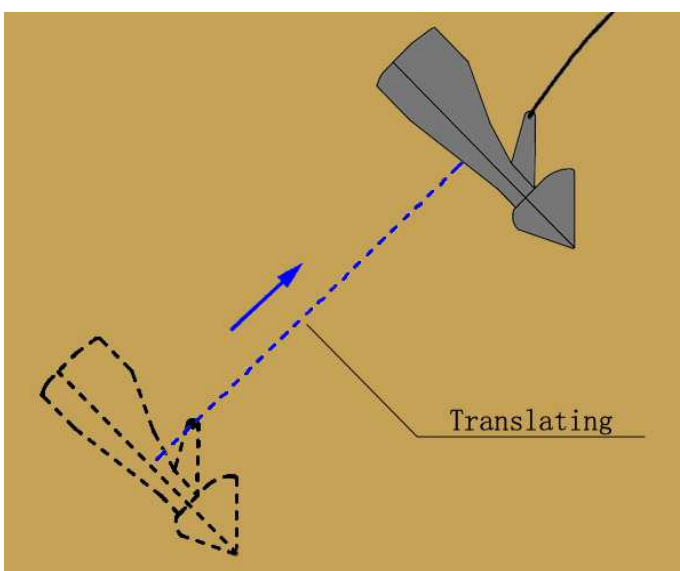

(b) 


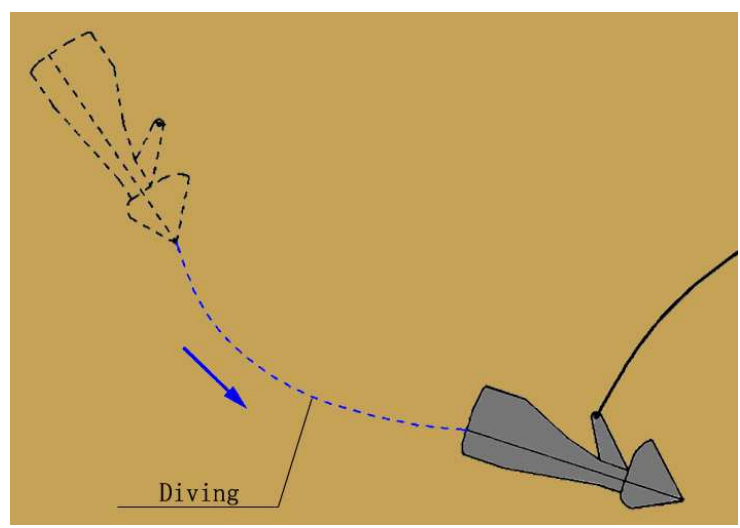

(c)

Fig. 7: Complex behaviors of the gravity installed anchor in seabed (a) Keying (b) Translating (c) Diving

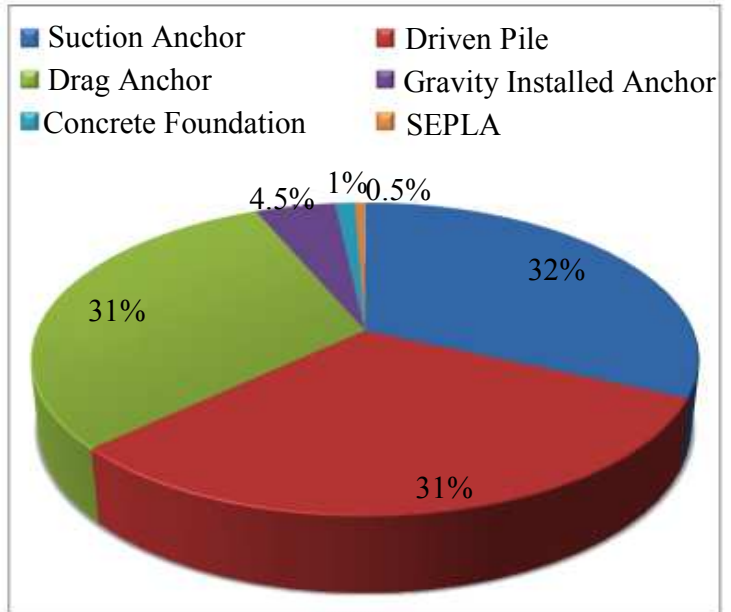

(a)

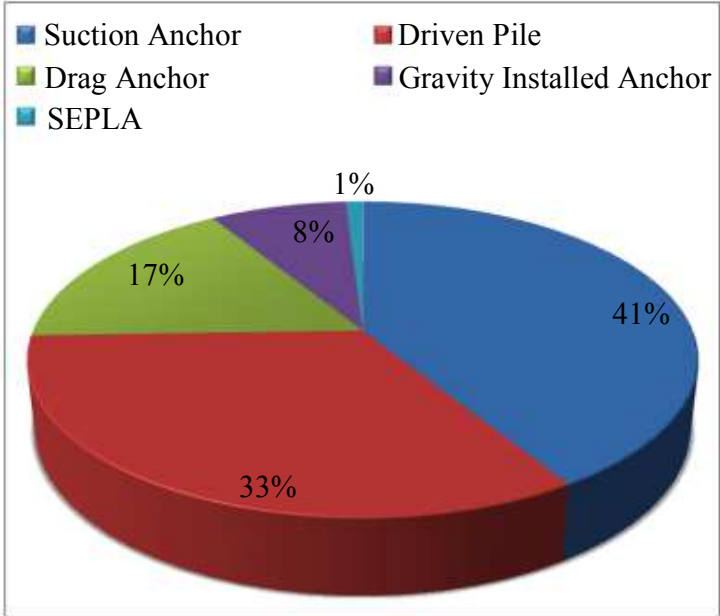

(b)

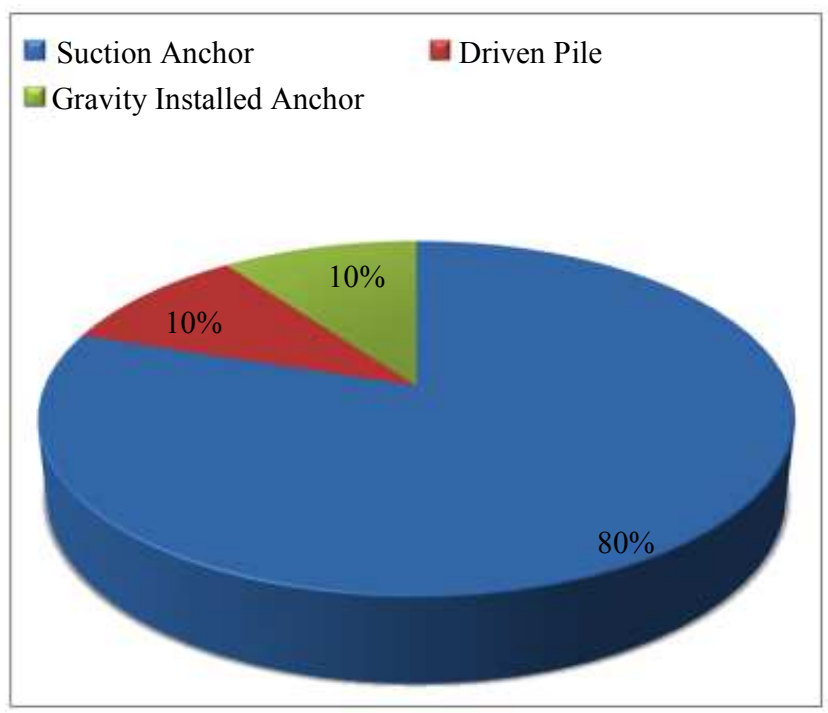

(c)

Fig. 8: Anchor types in the mooring system of oil and gas production platforms (a) Water depth between 15-2600 m (b) Water depth beyond $500 \mathrm{~m} \mathrm{(c)} \mathrm{Water} \mathrm{depth} \mathrm{beyond} 1500 \mathrm{~m}$ 


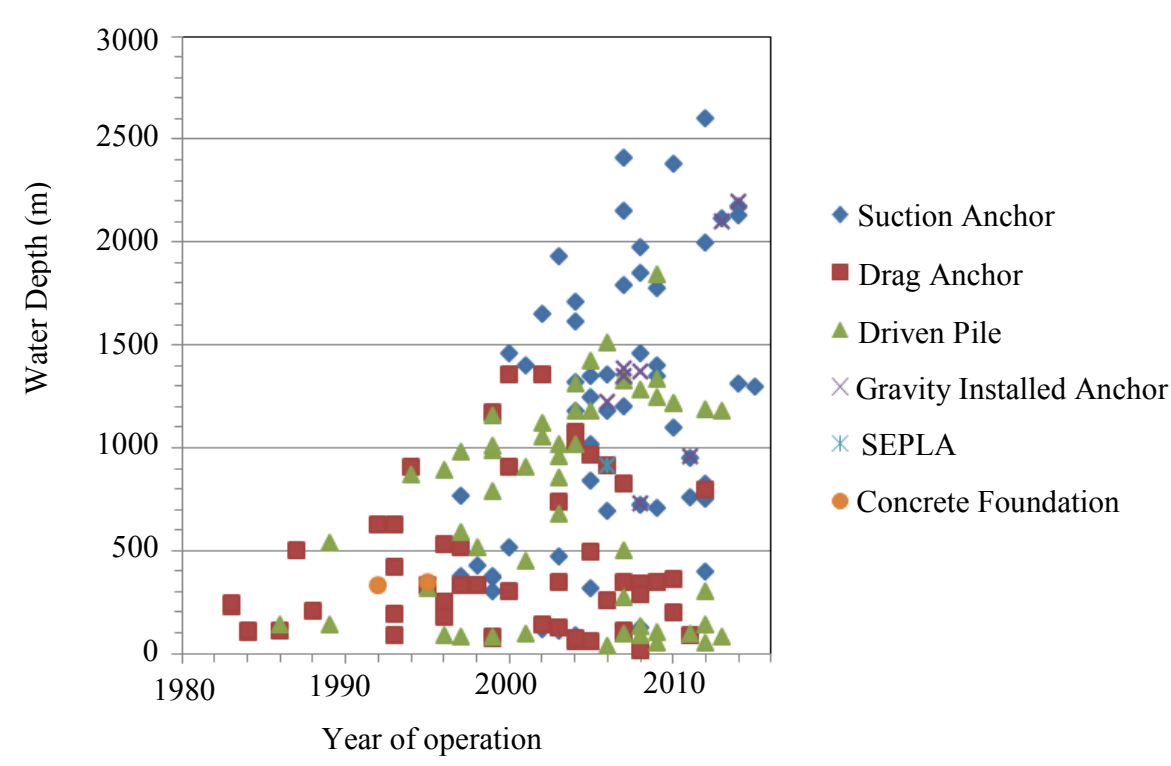

Fig. 9: Scatter plot of anchor type-water depth-year of operation

Table 3: Anchor types in the mooring system of oil and gas production platforms

\begin{tabular}{|c|c|c|c|c|c|c|c|}
\hline \multirow[b]{3}{*}{ Anchor type } & \multicolumn{7}{|c|}{ Number of cases (Total: 173 cases) } \\
\hline & \multicolumn{3}{|l|}{ Water depth } & \multicolumn{4}{|c|}{ Year of operation } \\
\hline & $15 \sim 2600 \mathrm{~m}$ & Beyond $500 \mathrm{~m}$ & Beyond $1500 \mathrm{~m}$ & $1981 \sim 1990$ & $1991 \sim 2000$ & 2001 2010 & $2011 \sim 2015$ \\
\hline Driven pile & 54 & 34 & 2 & 3 & 13 & 31 & 7 \\
\hline Suction anchor & 55 & 42 & 16 & 0 & 9 & 34 & 12 \\
\hline Drag anchor & 53 & 17 & 0 & 7 & 19 & 25 & 2 \\
\hline $\begin{array}{l}\text { Gravity installed } \\
\text { anchor }\end{array}$ & 8 & 8 & 2 & 0 & 0 & 5 & 3 \\
\hline SEPLA & 1 & 1 & 0 & 0 & 0 & 1 & 0 \\
\hline $\begin{array}{l}\text { Concrete } \\
\text { foundation }\end{array}$ & 2 & 0 & 0 & 0 & 2 & 0 & 0 \\
\hline
\end{tabular}

\section{Offshore Geotechnical Problems in Deepwater Mooring Techniques}

As interpreted above, many technical problems in deepwater mooring techniques are basically geotechnical ones. Actually, the core of the deepwater mooring research is believed to be offshore geotechnical problems. Here are several challenges in deepwater mooring techniques, summarized for our ongoing and future studies.

\section{Geological Survey of the Seabed and Evaluation of} Soil Properties Applied to Anchorage Engineering

For a large mooring system covering hundreds of square kilometers large or even more of the anchorage area, the geological survey is necessary to inspect complicated topography and potential hazards and to provide a feasibility analysis for the anchorage engineering. On the other hand, evaluation of engineering properties of soils is of great significance, which decides the bearing capacity and installation technique of anchors, the types of anchors and mooring and even the choice of positioning techniques. Advanced techniques and methods both in sites and laboratory, especially applied to anchorage engineering, are necessarily developed for efficient geological survey and precise evaluation.

\section{Key Techniques and Analytical Models during Anchor Installation}

The installation technique depends on the type of anchors, typically, the drag anchor and the GIA. The technical problem and analytical model are much different for different types of anchors. Previous studies were performed on the installation of drag anchors (Dahlberg and Strom, 1999; DNV, 2000; O’Neill and Randolph, 2001; Vryhof, 2005; Murff et al., 2005; Liu et al., 2012a; 2013; Zhao and Liu, 2015), SEPLAs (Dove et al, 1998; Aubeny et al., 2001; Song et al., 2008; Cassidy et al., 2012; Chen et al., 2015) and GIAs (Lieng et al., 1999; Medeiros, 2002; Shelton, 2007; Raie and Tassoulas, 2009; Lieng et al., 2010; O'Loughlin et al., 2013; Kim and Hossain, 2015; Liu et al., 2016a), which are helpful to improve the 
design and analysis of deepwater anchors. However, further studies are still expected on efficient and precise prediction methods, such as for the long-distance trajectory of drag anchors and the initial penetration and keying of GIAs.

\section{Complex Kinematic Mechanism and Behavior of Anchors in the Seabed}

The comprehensive anchor behaviors are not only the features of deepwater anchors, but also the basis of exhibiting non-catastrophic behavior. Clearer mechanisms of keying, translating and diving of different types of anchors are required, which would enhance the understanding of anchor-seabed-line interactional problems brought about by emerging deepwater anchors. Previous studies were performed on drag anchors (Neubecker and Randolph, 1996a; 1996b; Thorne, 1998; O’Neill and Randolph, 2001; O’Neill et al., 2003; Liu et al., 2010a; 2010b; Aubeny and Chi, 2010; Liu et al, 2012b; Zhang et al., 2014; Zhao and Liu, 2015; 2016), SEPLAs (Song et al., 2008; Yu et al., 2009; Wang et al., 2011; Yang et al., 2012; Cassidy et al., 2012; Chen et al., 2015; Zhao et al, 2016; Zhao and Liu, 2016) and GIAs (Raie and Tassoulas, 2009; O'Loughlin et al., 2013; Kim and Hossain, 2015; Wei et al., 2015; Zhao et al., 2016; Zhao and Liu, 2016; Liu et al., 2016b). The large deformation Finite Element Methods (FEMs), both the Remeshing and Interpolation Technique with Small Strain. (RITSS) method (Song et al, 2008; Wang et al., 2010a; 2011; Tian et al., 2014; Liu et al., 2016b) and the coupled Eulerian-Lagrangian (CEL) approach (Zhao and Liu, 2013; Tho et al., 2013; Zhao and Liu, 2015; Chen et al., 2015; Kim and Hossain, 2015; Liu et al., 2016a; Zhao et al., 2016; Zhao and Liu, 2016), have been proved to be efficient and powerful tools in analyzing anchor behaviors in the seabed. To clarify the conditions of keying, translating and diving, the theoretical model as well as the large deformation FEM need to be further developed.

Tension Transmitting and Profile Properties of the Embedded Mooring/Installation Line

For the installation of drag anchors, the movements of the anchor handling vessel, installation line and anchor are generally controlled as coplanar. The installation line embedded in soils presents a reverse catenary shape (Liu et al., 2012a; 2013; 2014a). However, for the TMS experiencing a hurricane and a possible floater drift, the movements of the floater, mooring line and anchor are noncoplanar. The mooring line embedded in soils will present a more complex shape in the three-dimensional space (Wang et al., 2010b; Martins and Lages, 2014). Further researches are encouraged to reflect some real complexities, such as different types of soils and complex soil properties, to develop theoretical models and to simulate complicated engineering cases as reported earlier (Zimmerman et al., 2009).

\section{Ultimate and Long-Term Cyclic Pullout Capacities} of the Anchor

As well known, for the structures deeply embedded in the seabed, the bearing capacity is significantly affected by the surrounding soils. The Ultimate Pullout Capacity (UPC) is an important index in designing and analyzing anchors. However, there are still uncertainties in determining the UPC through the load-displacement curves calculated from numerical analysis. There has not been a generally accepted criterion for determining the UPC and most existing criteria are not only uncertain but also irrational. Presently, the maximum resistance criterion based on the large deformation FE analysis is adopted to determine the UPC (Wang et al., 2010a; Liu et al., 2014b), which overcomes the shortages of other existing criteria. The pullout capacity of anchors subjected to long-term cyclic loading relates directly to the cyclic behavior of soils and is still a great concern of researchers. The bounding-surface plasticity model is being developed to find an analytical procedure of cyclic pullout capacity for anchors both in clay and sand (Hu et al., 2012; Hu and Liu, 2014). The developed model would also contribute to the current design practice, such as by means of cyclic contour diagrams (DNV, 2002; ABS, 2017), by calculating the cyclic shear strength at different stress conditions and constructing more detailed contour diagrams.

\section{Measurement Techniques and Methods for Experimentally Investigating Deepwater Anchors}

To measure the anchor trajectory precisely in laboratory is actually not an easy task, since the performance of the anchor completely embedded in saturated soils cannot be directly observed. It has been realized that some advanced techniques, including radar, infrared light, X-ray and lasers, are all not feasible due to the combined concerns of measurement precision, safety and economy. The contact measurement technique based on various transducers was successfully developed in experimentally investigating drag anchors and embedded lines (Zhang et al., 2011; Liu et al., 2014a), but may not be effective enough to monitor the somewhat random trajectory of GIAs in a three-dimensional space. To develop laboratory measurement techniques for deeply embedded structures and to monitor and measure the orientation and trajectory of anchors, is still a great challenge.

\section{Conclusion}

The present work outlines the positioning techniques for offshore large floating structures. Surveys and statistical analysis are specially performed to demonstrate the strategic importance of deepwater mooring techniques, especially the taut-wire mooring system. Being a common 
and key technique for large floating structures, the deepwater mooring is the most efficient long-term and permanent positioning technique. Meanwhile, it also plays a vital role in safety insurance of the floating structure during extreme sea environments. Due to that the mooring system is very sensitive to the water depth and is extremely risky and challenging part of the floating system, it is actually the bottleneck of ocean space utilization and resource exploitation in deep waters.

An engineering case is introduced to demonstrate the specialities of the deepwater mooring research, which are brought about in design and analysis of deepwater mooring techniques due to the special mooring pattern, material property of synthetic fiber ropes and performance of deepwater anchors.

Deepwater anchors are outlined with emphasis due to the key role of anchors in the mooring system. Because of specific installation technique and structural performance and the complexities of marine environments, there are lots of interesting technical and scientific problems for deepwater anchors no matter in installation or mooring, which are deserved to be further investigated. All these problems need to be solved by developing new analytical methods by combining the mechanism, theory, experiment and numerical simulation.

The core of the deepwater mooring research is believed to be offshore geotechnical problems. Six challenges in deepwater mooring techniques as well as associated investigations are summarized for our ongoing and future studies, including geological survey of the seabed and evaluation of soil properties applied to anchorage engineering, key techniques and analytical models during anchor installation, complex kinematic mechanism and behavior of anchors in the seabed, tension transmitting and profile properties of the embedded mooring/installation line, ultimate and long-term cyclic pullout capacities of the anchor and measurement techniques and methods for experimentally investigating deepwater anchors.

\section{Acknowledgement}

Financial support from the National Natural Science Foundation of China (Grant no. 51539008) and the Key Project of Tianjin Research Program of Application Foundation and Advanced Technology (14JCZDJC39900) is greatly acknowledged.

\section{Author's Contributions}

Haixiao Liu: Organized the research and writing of the paper.

Zhou Li: Contributed the statistical analysis in the paper.

Yuming Zhang: Contributed the statistical analysis in the paper.

\section{Ethics}

We guarantee the truth of all data and the originality of this paper.

\section{References}

ABS, 2017. Guidance notes on design and installation of drag anchors and plate anchors.

Aubeny, C.P. and C. Chi, 2010. Mechanics of drag embedment anchors in a soft seabed. J. Geotech. Geoenviron. Eng.

DOI: 10.1061/(ASCE)GT.1943-5606.0000198

Aubeny, C.P., D.J. Murff and J.M. Roesset, 2001. Geotechnical issues in deep and ultra deep waters. Int. J. Geomech.

DOI: 10.1061/(ASCE)1532-3641(2001)1:2(225)

Cassidy, M.J., C. Gaudin, M.F. Randolph, P.C. Wong and D. Wang et al., 2012. A plasticity model to assess the keying of plate anchors. Geotechnique, 62: 825-836. DOI: 10.1680/geot.12.OG.009

Chen, Z., K.K. Tho, C.F. Leung and Y.K. Chow, 2015. Large deformation numerical analysis of plate anchor keying process. Proceedings of the 3rd ISFOG, (ISFOG' 15), Oslo, Norway, pp: 845-850.

Dahlberg, R. and P.J. Strøm, 1999. Unique onshore tests of deepwater drag-in plate anchors. Proceedings of the 31st Offshore Technology Conference, May 3-6, Houston, USA. DOI: 10.4043/10989-MS

DNV, 2000. Design and installation of fluke anchors in clay. Recommended Practice RP-E301. DNV RP-E301.

DNV, 2002. Design and installation of plate anchors in clay. Recommended Practice RP-E302. DNV RP-E302.

Dove, P., H. Treu and B. Wilde, 1998. Suction Embedded Plate Anchor (SEPLA): A new anchoring solution for ultra-deepwater mooring. Proceedings of the DOTC, (DOTC' 98), New Orleans, USA.

$\mathrm{Hu}$, C. and H.X. Liu, 2014. Implicit and explicit integration schemes in the anisotropic bounding surface plasticity model for cyclic behaviours of saturated clay. Comput. Geotech., 55: 27-41. DOI: 10.1016/j.compgeo.2013.07.012

Hu, C., H.X. Liu and W. Huang, 2012. Anisotropic bounding-surface plasticity model for the cyclic shakedown and degradation of saturated clay. Comput. Geotech., 44: 34-47.

DOI: 10.1016/j.compgeo.2012.03.009

Kim, Y H. and M.S. Hossain, 2015. Dynamic installation of OMNI-Max anchors in clay: Numerical analysis. Geotechnique, 65: 1029-1037. DOI: 10.1680/jgeot.15.T.008

Lieng, J.T., F. Hove and T.I. Tjelta, 1999. Deep penetrating anchor: subseabed deepwater anchor concept for floaters and other installations. Proceedings of the 9th ISOPE, (ISOPE’ 99), Brest, France. 
Lieng, J.T., T.I. Tjelta and K. Skaugset, 2010. Installation of two prototype deep penetrating anchors at the Gjoa Field in the North Sea. Proceedings of the 42nd Offshore Technology Conference, May 3-6, Houston, USA. DOI: $10.4043 / 20758-M S$

Liu, H.X., Y. Li, H.T. Yang, W. Zhang and C.L. Liu, 2010a. Analytical study on the ultimate embedment depth of drag anchors. Ocean Eng., 37: 1292-1306. DOI: 10.1016/j.oceaneng.2010.06.007

Liu, H.X., W. Zhang, X.W. Zhang and C.L. Liu, 2010 b. Experimental investigation on the penetration mechanism and kinematic behavior of drag anchors. Applied Ocean Res., 32: 434-442. DOI: 10.1016/j.apor.2010.09.004

Liu, H.X., C.L. Liu, H.T. Yang, Y. Li and W. Zhang et al., 2012a. A novel kinematic model for drag anchors in seabed soils. Ocean Eng., 49: 33-42.

DOI: 10.1016/j.oceaneng.2012.04.013

Liu, H.X., C.L. Liu, Y.B. Zhao and C. Wang, 2013. Reverse catenary equation of the embedded installation line and application to the kinematic model for drag anchors. Applied Ocean Res., 43: 80-87. DOI: 10.1016/j.apor.2013.08.002

Liu, H.X., C.L. Liu, Y.B. Zhao and C. Wang, 2014a. Comparative study of reverse catenary properties of the installation line for drag anchors. Applied Ocean Res., 48: 42-54. DOI: 10.1016/j.apor.2014.07.011

Liu, H.X., F.M. Su and Z. Li, 2014b. The criterion for determining the ultimate pullout capacity of plate anchors in clay by numerical analysis. Am. J. Eng. Applied Sci., 7: 374-386.

DOI: 10.3844/ajeassp.2014.374.386

Liu, H.X., K. Xu and Y.B. Zhao, 2016a. Numerical investigation on the penetration of gravity installed anchors by a coupled Eulerian-Lagrangian approach. Applied Ocean Res., 60: 94-108. DOI: 10.1016/j.apor.2016.09.002

Liu, J., L. Lu and Y. Hu, 2016b. Keying behavior of gravity installed plate anchor in clay. Ocean Eng., 114: 10-24. DOI: 10.1016/j.oceaneng.2016.01.018

Liu, H.X., W. Zhang, C.L. Liu and C. Hu, 2012b. Movement direction of drag anchors in seabed soils. Applied Ocean Res., 34: 78-95.

DOI: 10.1016/j.apor.2011.09.007

Martins, M.A.L. and E.N. Lages, 2014. On the formulation of three-dimensional inverse catenary for embedded mooring line modeling. Comput. Model. Eng. Sci., 102: 449-474.

DOI: $10.3970 / \mathrm{cmes} .2014 .102 .449$

Medeiros, C.J., 2002. Low cost anchor system for flexible risers in deep waters. Proceedings of the 34th Offshore Technology Conference, May 6-9, Houston, USA. DOI: 10.4043/14151-MS
Murff, J.D., M.F. Randolph and S. Elkhatib, et al., 2005. Vertically loaded plate anchors for deepwater applications. Proceedings of the 1st International Symposium on Frontiers in Offshore Geotechnics, (FOG' 05), Perth, Australia, pp: 31-48.

Neubecker, S.R. and M.F. Randolph, 1996a. The kinematic behaviour of drag anchors in sand. Can. Geotech. J., 33: 584-594. DOI: 10.1139/t96-084-306

Neubecker, S.R. and M.F. Randolph, 1996b. The performance of drag anchor and chain systems in cohesive soil. Mar. Georesour. Geotec., 14: 77-96. DOI: $10.1080 / 10641199609388305$

Nielsen, F.G. and A.U. Bindingbø, 2000. Extreme loads in taut mooring lines and mooring line induced damping: an asymptotic approach. Applied Ocean Res., 22: 103-118. DOI: 10.1016/S0141-1187(99)00026-7

O’Loughlin, C.D., M.D. Richardson, M.F. Randolph and C. Gaudin, 2013. Penetration of dynamically installed anchors in clay. Geotechnique, 63: 909-919. DOI: 10.1680/geot.11.P.137

O’Neill, M.P., M.F. Bransby and M.F. Randolph, 2003. Drag anchor fluke-soil interaction in clays. Can. Geotech. J., 40: 78-94. DOI: 10.1139/t02-096

O’Neill, M.P. and M.F. Randolph, 2001. Modelling drag anchors in a drum centrifuge. Int. J. Phys. Model. Geo., 1: 29-41. DOI: 10.1680/ijpmg.2001.010203

Raie, M.S. and J.L. Tassoulas, 2009. Installation of torpedo anchors: numerical modeling. J. Geotech. Geoenviron. Eng., 135: 1805-1813. DOI: 10.1061/(ASCE)GT.1943-5606.0000159

Shelton, J.T., 2007. OMNI-Maxtrade anchor development and technology. Proceedings of the OCEANS, Sept. 29-Oct. 4, IEEE Xplore Press, Vancouver, Canada, pp: 1-10. DOI: 10.1109/OCEANS.2007.4449415

Song, Z., Y. Hu and M.F. Randolph, 2008. Numerical simulation of vertical pullout of plate anchors in clay. J. Geotech. Geoenviron. Eng., 134: 866-875. DOI: 10.1061/(ASCE)1090-0241(2008)134:6(866)

Tho, K.K., Z. Chen, C.F. Leung and Y.K. Chow, 2014. Pullout behaviour of plate anchor in clay with linearly increasing strength. Can. Geotech. J., 51: 92-102. DOI: 10.1139/cgj-2013-0140

Thorne, C.P., 1998. Penetration and load capacity of marine drag anchors in soft clay. J. Geotech. Geoenviron. Eng., 124: 945-953.

DOI: 10.1061/(ASCE)1090-0241(1998)124:10(945)

Tian, Y.H., C. Gaudin and M.J. Cassidy, 2014. Improving plate anchor design with a keying flap. J. Geotech. Geoenviron. Eng., 140(5): 04014009. DOI: 10.1061/(ASCE)GT.1943-5606.0001093

Vryhof, A., 2005. Anchor manual. Krimpen ad Yssel, The Netherlands. 
Wang, D., Y.X. Hu and M.F. Randolph, 2010a. Threedimensional large deformation finite-element analysis of plate anchors in uniform clay. $\mathrm{J}$. Geotech. Geoenviron. Eng., 136: 355-365. DOI: 10.1061/(ASCE)GT.1943-5606.0000210

Wang, D., Y.X. Hu and M.F. Randolph, 2011. Keying of rectangular plate anchors in normally consolidated clays. J. Geotech. Geoenviron. Eng., 137: 1244-1253. DOI: 10.1061/(ASCE)GT.1943-5606.0000477

Wang, L.Z., Z. Guo and F. Yuan, 2010b. Threedimensional interaction between anchor chain and seabed. Applied Ocean Res., 32: 404-413.

DOI: 10.1016/j.apor.2010.09.001

Wei, Q.C., M.J. Cassidy, Y.H. Tian, C. Gaudin and C.D. O'Loughlin, 2015. Behaviour of OMNI-Max anchors under chain loading. Proceedings of the 3rd ISFOG, (FOG' 15), Oslo, Norway, pp: 925-930.

Yang, M., C.P. Aubeny and J.D. Murff, 2012. Behavior of suction embedded plate anchors during keying process. J. Geotech. Geoenviron. Eng., 138: 174183. DOI: 10.1061/(ASCE)GT.1943-5606.0000582

$\mathrm{Yu}$, L., J. Liu, X.J. Kong and Y. Hu, 2009. Threedimensional numerical analysis of the keying of vertically installed plate anchors in clay. Comput. Geotech., 36: 558-567. DOI: 10.1016/j.compgeo.2008.10.008

Zhang, W., H.X. Liu, Y.B. Zhao and Y.Z. Yue, 2014. Interactional properties between drag anchor and installation line. J. Geotech. Geoenviron. Eng., 140: 04013018.

DOI: 10.1061/(ASCE)GT.1943-5606.0001035
Zhang, W., H.X. Liu, H.F. Zhou and Z.G. Sheng, 2011. A new technique to measure the trajectory of drag anchors in soils. Geotech. Test. J., 34: 279-287. DOI: $10.1520 / \mathrm{GTJ} 103353$

Zhao, Y.B. and H.X. Liu, 2013. Large deformation finite element analysis of the anchor line embedded in seabed soils. Proceedings of the 32nd International Conference on Ocean, Offshore and Arctic Engineering, June 9-14, Ocean, Offshore and Arctic Engineering Division, Nantes, France, pp: V006T10A024. DOI: 10.1115/OMAE2013-10586

Zhao, Y.B. and H.X. Liu, 2015. The drag effects on the penetration behavior of drag anchors during installation. Ocean. Eng., 109: 169-180. DOI: 10.1016/j.oceaneng.2015.09.011

Zhao, Y.B. and H.X. Liu, 2016. Numerical implementation of the installation/mooring line and application to analyzing comprehensive anchor behaviors. Applied Ocean Res., 54: 101-114. DOI: 10.1016/j.apor.2015.10.007

Zhao, Y.B., H.X. Liu and P.D. Li, 2016. An efficient approach to incorporate anchor line effects into the coupled Eulerian-Lagrangian analysis of comprehensive anchor behaviors. Applied Ocean Res., 59: 201-215. DOI: 10.1016/j.apor.2016.06.005

Zimmerman, E.H., M.W. Smith and J.T. Shelton, 2009. Efficient gravity installed anchor for deepwater mooring. Proceedings of the 41st Offshore Technology Conference, May 4-7, Houston, USA. 